" 4 " antigens. In the single instance in which the fourth mismatched antigen was identified it was HL-A5.

The possibility of there being third and fourth HL-A subloci has been raised by Walford et al. (1969). If such should be the case, and the strength of their alleles proves to be comparable to those of the "LA" and "4" subloci, the results in this series could be readily explained. Moreover, unless their antigenic determinants are more strongly associated with those of other subloci than has been demonstrated for "LA" and "4" alleles (Sharp et al., 1970), it will be virtually impossible to achieve identical matching of donor and recipient.

Knowledge concerning immunological interrelationships, as distinct from genetic associations, in the HL-A system is scanty, as are data concerning the role of non-HL-A antigens other than those of the ABO system. The observation that no combination of mismatched recognized antigens was associated with early acute rejection in the present series does not rule out a synergistic action between antigens, for the number of rejected grafts was small and a significant proportion of antigens were not identified.

We believe that incompatibility of the less easily recognized HL-A antigens, and presensitization without formation of detectable cytotoxic antibodies, will prove to be major factors determining the early acute rejection of allografts from unrelated donors.

We wish to acknowledge the team-work and assistance of our colleagues at Sydney, Prince Henry, Royal Prince Alfred, and St. Vincent's Hospitals, particularly Professor G. F. Murnaghan, Dr. J. R. Johnson, Mr. J. May, Dr. J. Hayes and Mr. R. A. Lord, and Dr. G. T. Archer, Director of the New South Wales Red Cross Blood Transfusion Service.

\section{REFERENCES}

Dausset, J., Rapaport, F. T., Ivanyi, P., and Colombani, J.((1965). Series Haematologica, No. i1, p. 63.

Kincaid-Smith, P. (1967). Lancet, 2, 849.

Kissmeyer-Nielsen, F., Olsen, S., Petersen, V. P., and Fjeldborg, O. (1966). Lancet, 2, 662.

Kissmeyer-Nielsen, F., Sveigaard, A., and Hauge, M. (1968). Nature, 219, 1116.

Manzler, A. D. (1968). Transplantation, 6, 787.

Morris, P. J., Mickey, M. R., Singal, D. P., and Terasaki, P. I. (1969), British Medical fournal, $1,758$.

Patel, R., Mickey, M. R., and Terasaki, P. I. (1968). New England fournal of Medicine, 279, 501 .

Patel, R., and Terasaki, P. I. (1969). New England fournal of Medicine, 280, 735 .

Porter, K. A., et al. (1963). British Medical fournal, 2, 639.

Rood, J. J. van, et al. (1965). Series Haematologica, No. 11, p. 37.

Sharp, A. M., Cook, K. M., and Johnston, J. M. (1970). Nature. In press.

Sheil, A. G. R., et al. (1968). Medical fournal of Australia, 2, 1079.

Sheil, A. G. R., et al. (1969). Lancet, 2, 917.

Singal, D. P., Mickey, M. R., and Terasaki, P. I. (1969). Transplantation, $7,246$.

Stewart, J. H., et al. (1969). Lancet, 1, 176.

Stickel, D. L., Amos, D. B., Zmijewski, C. M., Glenn, J. F., and Robinson, R. R. (1967). Transplantation, 5, 1024 .

Terasaki, P. I., Thrasher, D. L., and Hauber, T. H. (1968). Advance in Transplantation, ed. J. Dausset, J. Hamburger, and G. Mathé, p. 225, Copenhagen, Munksgaard.

Terasaki, P. I., Vredevoe, D. L., and Mickey, M. R. (1967). Transplantation, 5,1057 .

Tracy, G. D., Annetts, D. L., Farnsworth, R. H., Jeremy, D., and Murnaghan, G. F. (1969).' Australian and New Zealand fournal of Surgery, 39, 26.

Viza, D. C., Degani, O., Dausset, J., and Davies, D. A. L. (1968). Nature, $219,704$.

Walford, R. L. (1969). Series Haematologica, 2, No. 2.

Walford, R. L., Gallagher, R., and Sjaarda, J. R. (1964). Science, 144, 868. Walford, R. L., Zeller, E., Finklestein, S., Waters, H., and Smith, G. S. (1969). Proceedings of the 12th Congress of the International Society of Blood Transfusion, Moscow.

\title{
Loss of Skeletal Calcium by Patients on Maintenance Dialysis
}

\author{
P. J. ATKINSON, ${ }^{*}$ L.R.C.P., M.R.C.S., PH.D. ; R. R. WEST, † M.A., PH.D. ; F. M. PARSONS, $\ddagger$ M.D., B.SC., F.R.C.P.ED. \\ G. W. REED, $\$ M.SC.
}

British Medical fournal, 1970, 3, 490-492

Summary: Direct radiological measurements of the min$\checkmark$ eral content of femoral bone were performed in 13 patients on maintenance dialysis. They were found to be sufficiently sensitive to be used for monitoring, and it is suggested that the technique gives more information than do calcium-balance studies.

\section{Introduction}

Maintenance dialysis reduces the severity of uraemia and prolongs the lives of patients with chronic renal failure. Nevertheless, the prevalence and the development of metabolic bone disease in these patients would suggest that there is a basic abnormality of calcium metabolism that is not yet adequately controlled by dialysis. Though Curtis et al. (1969) have shown that osteodystrophic lesions can be resolved by maintaining an optimal calcium level in dialysis fluids, a tendency for bone resorption to occur and calcium to

\footnotetext{
* Research Lecturer, Biological Research Unit, Dental School and Hospital, University of Leeds, Leeds 1 .

+ Research Assistant, Department of Medical Physics, University of Leeds, Leeds 1. Now at Department of Mathematical Statistics,
Leed University College, Cardiff.

₹ Consultant in Clinical Renal Physiology, the General Infirmary at Leeds, Leeds 1 .

Senior Lecturer, Department of Medical Physics, University of Leeds,
} Leeds 1 . be deposited in soft tissues is the more usual experience (Kleeman et al., 1969). Consequently the loss of calcium from the body, as measured in metabolic balance studies, may not give reliable information about the changes that have occurred in the bone. To resolve some of these difficulties it would be an advantage if direct measurements of bone mineral were made at regular intervals in patients treated by dialysis.

\section{Method}

This communication describes direct measurements of bone mineral that have been made on 13 patients receiving maintenance dialysis: 6 of these were treated by peritoneal dialysis and 7 by haemodialysis. Their renal function was either negligible or absent, most haemodialysis subjects having had a total nephrectomy.

The duration of the peritoneal dialysis varied between 30 and 35 hours and was repeated at weekly intervals; 2 litres of dialysis fluid was used at each hourly exchange. The calcium concentration of the dialysate was $7.2 \mathrm{mg} . / 100 \mathrm{ml}$. and the normal sodium, chloride, water ratios in plasma were maintained by the occasional addition of 1 litre of $5 \%$ dextrose in place of 1 litre of dialysis fluid (Moriarty and Parsons, 1966). The mean reduction of blood urea concentration by the dialysis was $55 \%$, and the creatinine was reduced by $36 \%$ 
during the same period (mean post-dialysis values for urea and creatinine were 112 and $15 \mathrm{mg} . / 100 \mathrm{ml}$. respectively). Serum calcium levels remained within the normal range, both before and after dialysis.

The average weekly duration of haemodialysis was also around 30 hours, but was divided into three equally spaced sessions of 10 hours' duration. The calcium concentration of the dialysis fluid was maintained between 6.1 and 6.3 mg./100 ml. The mean reduction in blood urea concentration by this procedure was $65 \%$ and creatinine $52 \%$ (mean postdialysis values for urea and creatinine were 45.5 and 5.9 $\mathrm{mg} . / 100 \mathrm{ml}$. respectively). In this procedure also the serum calcium did not vary outside the normal range.

\section{Results}

The results reported here were obtained from measuremenis taken at regular intervals over a period of 36 weeks. The method, which has been described previously (Reed et al., 1970; West and Reed, 1970), employs the 60 $\mathrm{KeV}$ emission from the radioisotope americium-241. A finely collimated beam is directed through the part to be measured (the femur in the present series) and the transmitted radiation is recorded by a scintillation counter. The attenuation that occurs is related to the masses of bone and soft tissue traversed. The beam is always scanned across the same part of the leg, which is supported in a parallel-sided Perspex trough. The recorded logarithmic count rate presents a profile of the bone bounded on each side by a baseline representing the constant thickness of soft tissue enclosed by the trough (Fig. 1). The area between trace and baseline

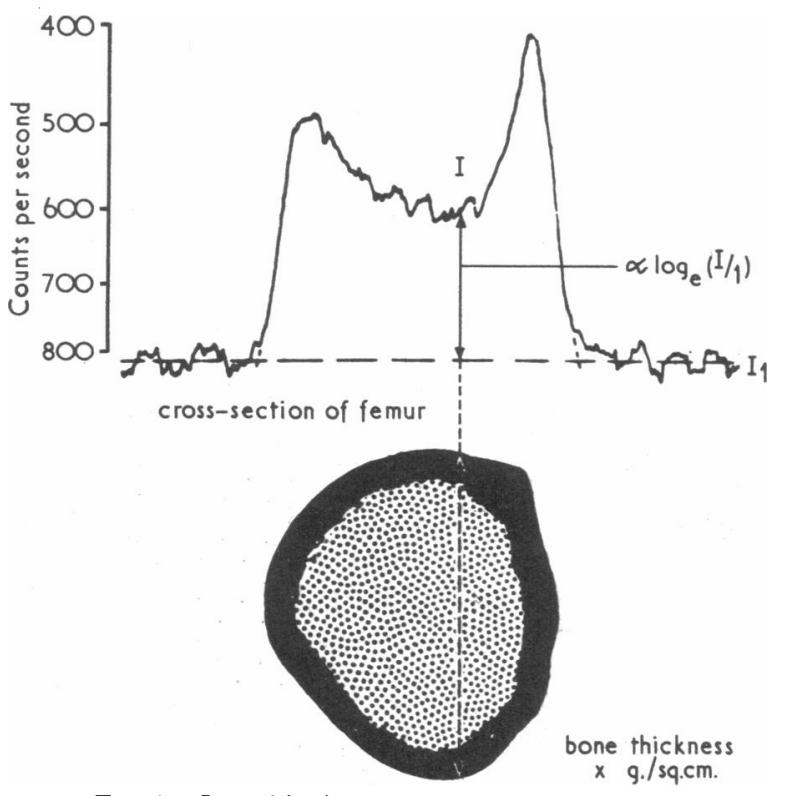

FIG. 1.-Logarithmic count-rate trace of femur.

is related to the mineral content of the femoral shaft, and its evaluation gives a 'bone index' expressed as the mass of bone, in terms of a selected standard, per unit length of the femur. For our standard we have used mean results for 10 powdered specimens of cortical and cancellous bone. The area integration sums the various values of the bone thickness $(x)$ across the scan. The quantity $\mathrm{x}$ is given by

where:

$$
x=\frac{\log _{e} I_{1} / I}{\mu_{x}-\mu_{y}} \rho x \text { g./sq. cm. }
$$

$I_{1}=$ Mean count rate through the soft tissue.

$I=$ Count rate through bone and soft tissue at any point during the scan.

$\mu_{x}=$ Linear attenuation coefficient of the standard bone.

$\mu_{y}=$ Linear attenuation coefficient of soft tissue.

$\rho x=$ Density of the standard bone.
The reproducibility for repeated measurements of the bone index is of the order $\pm 2 \%$ and is better than for most radiographic procedures. The radiation dose to the part of the leg scanned is of the order of $0.1 \mathrm{mrem}$, so that the number of measurements that can be made in an extended study, such as the present one, is not restricted.

The results obtained are given in the Table, and plots for two patients are presented in Fig. 2. The upper plot is for a man on haemodialysis (Case 9) and shows a fall in bone index

Results of Study

\begin{tabular}{|c|c|c|c|c|c|}
\hline $\begin{array}{l}\text { Case } \\
\text { No. }\end{array}$ & Age & Sex & Treatment & $\begin{array}{l}\text { Rate of Change of } \\
\text { Bone Index } \\
\text { (\% per } 10 \text { weeks) }\end{array}$ & $\begin{array}{l}\text { Correlation } \\
\text { Coefficient }\end{array}$ \\
\hline $\begin{array}{r}1 \\
2 \\
3 \\
4 \\
5 \\
6 \\
7 \\
7 \\
8 \\
9 \\
10 \\
11 \\
12 \\
13\end{array}$ & $\begin{array}{l}18 \\
35 \\
39 \\
41 \\
44 \\
55 \\
24 \\
39 \\
41 \\
42 \\
42 \\
47 \\
49\end{array}$ & $\begin{array}{l}\text { F. } \\
\text { F. } \\
\text { F. } \\
\text { F. } \\
\text { F. } \\
\text { F. } \\
\text { M. } \\
\text { M. } \\
\text { M. } \\
\text { M. } \\
\text { F. } \\
\text { F. }\end{array}$ & $\begin{array}{c}\text { Peritoneal dialysis } \\
\text { ”, } \\
\text { \#, } \\
\text { Haemodialysis } \\
\text { ”, } \\
\text { ”, } \\
\text { ”, }\end{array}$ & $\begin{array}{l}-4.7 \\
-1.8 \\
-2.0 \\
-0.6 \\
-4.4 \\
-5.5 \\
-1.9 \\
+0.9 \\
-1.2 \\
-0.8 \\
-0.4 \\
-2.3 \\
-2.4\end{array}$ & $\begin{array}{l}0.62 \\
0.53 \\
0.56 \\
0.11 \\
0.79 \\
0.73 \\
0.62 \\
0.32 \\
0.63 \\
0.17 \\
0.30 \\
0.36 \\
0.66\end{array}$ \\
\hline
\end{tabular}

*Bone index is expressed in $\mathbf{g} . / \mathrm{cm}$.

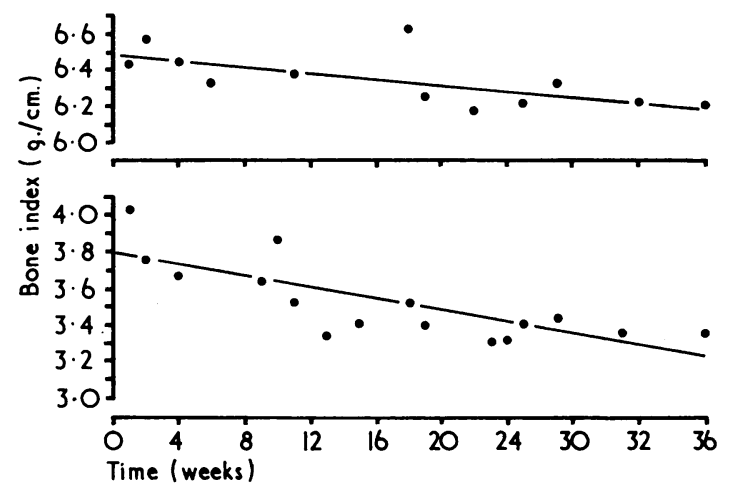

Fig. 2.-Upper: Plot of Case 9. Lower: Plot of Case 5.

of $1.2 \%$ in 10 weeks. The lower plot is for a woman on peritoneal dialysis (Case 5) and shows a fall of $4.4 \%$ in the same period. Coefficients of correlation for these regressions are $\mathbf{0 . 6}$ and 0.8 respectively. A bone loss was observed for most patients, though for some it was small and for one (Case 8) a slight gain was indicated. In general the rate of bone loss for patients on haemodialysis was less than for those on peritoneal dialysis; the mean rates for the two groups were $1.5 \%$ in 10 weeks and $3.2 \%$ in 10 weeks respectively.

\section{Discussion}

The extent to which changes in femoral bone index are related to those in the whole skeleton in chronic renal failure is not known. Observations on dried, apparently normal skeletons show a high degree of correlation between femoral bone index and total skeletal mass $(r=0.86)$ (West, unpublished data). In chronic renal disease, however, it is generally believed from radiographic evidence that, as a result of abnormal parathyroid activity, some areas of the skeleton are more susceptible to resorption than others, as for instance in subperiosteal regions and the terminal phalanges. These radiographic manifestations of renal disease probably do not indicate the full extent of the bone involvement.

The failure to maintain bone equilibrium continues during dialysis but may not be due entirely to resorptive changes. Bone formation is reduced, presumably by the toxic effects of uraemia (Jowsey et al., 1969), and the time of maturation is still significantly prolonged even when uraemia is diminished during dialysis (Sarnsethsiri et al., 1969). In addition, patients with chronic renal disease may be less mobile than normal, 
though it is thought unlikely that the loss of mobility led to any undue change in the rate of bone resorption during dialysis in the present study. All subjects were treated as outpatients and between treatments carried out a near-normal daily activity.

Despite the possibility that these factors influence calcium metabolism and thereby affect direct measurements of the bone, our results indicated a gradual loss of bone with time. The loss was greater after peritoneal dialysis than after haemodialysis, and this may be accounted for by differences occurring in the calcium balance, both in the alimentary tract and in the dialysis system. This aspect is currently being investigated. Though it is not yet established whether changes in bone index truly represent total skeletal change, direct measurements of the mineral content of femoral bone have proved sufficiently sensitive to be used for monitoring patients on regular dialysis for renal disease. We suggest that this method gives additional information which is not provided by the present form of balance study. Furthermore, it can be applied to long-term assessment of therapy designed to restore calcium balance while the patient is living at home and undertaking normal activity.

\section{REFERENCES}

Curtis, J. R., et al. (1969). Quarterly fournal of Medicine, 38, 49.

Jowsey, J., Massry, S. G., Coburn, J. W., and Kleeman, C. R. (1969). Archives of Internal Medicine, 124, 539.

Kleeman, C. R., Massry, S. G., Coburn, J. W., and Popovtzer, M. M. (1969). Archives of Internal Medicine, 124, 262.

Moriarty, M. V., and Parsons, F. M. (1966). British fournal of Urology, 38,

623. W., West, R. R., and Atkinson, P. J. (1970). Proceedings of Symposium Ossium. In press. Sarnsethsiri, P., Jaworski, Z. F., Shimizu, A. G., and Frost, H. M. (1969).
Archives of Pathology, 88, 49 .

West, R. R., and Reed, G. W. (1970). In preparation.

\title{
Circulating Rheumatoid and Antinuclear Factors in Asbestos Workers
}

\author{
MARGARET TURNER-WARWICK, ${ }^{*}$ D.M., PH.D., F.R.C.P. ; W. RAYMOND PARKES, $\dagger$ M.D., M.R.C.P., D.I.H.
}

\begin{abstract}
Summary: In an unselected series of 80 patients with asbestos exposure referred to the London Pneumoconiosis Medical Panel, antinuclear and rheumatoid factors were found in 28 and $27 \%$ respectively. This probably represents at least a fourfold increase over their incidence in random populations. The presence of these autoantibodies was not related to the duration of exposure, but was related to the extent of radiographic abnormality.
\end{abstract}

\section{Introduction}

It has been shown (Turner-Warwick and Doniach, 1965) that there is an increased prevalence of antinuclear and rheumatoid factors in patients with the clinical syndrome of cryptogenic fibrosing alveolitis (idiopathic diffuse interstitial pulmonary fibrosis). Similarity between this syndrome and the clinical and pathological features seen in asbestosis suggested the possibility of circulating autoantibodies being found in persons with asbestosis. Pernis and Vigliani (1965) have reported an increased prevalence of rheumatoid factor in asbestos workers, especially those with abnormal chest radiographs; the overlap between asbestosis and "rheumatoid" diseases is further suggested by the rare occurrence of necrobiotic nodules in the lungs in asbestos workers (Rickards and Barrett, 1958; Tellesson, 1961; Morgan, 1964). We know of no published reports of circulating antinuclear factors in asbestosis. Studies of other pneumoconioses, especially that due to inhalation of coal dust, have already shown an association between certain radiographic features and the presence of both clinical rheumatoid arthritis and circulating rheumatoid factor (Caplan, 1953; Caplan et al., 1962; Lindars and Davies, 1967).

\section{Materials and Methods}

Subjects Studied.-Serum samples were collected from an unselected series of 80 people with a history of exposure to asbestos who were referred to the Pneumoconiosis Medical

\footnotetext{
* Consultant Physician, Brompton Hospital, London S.W.3, and London Chest Hospital, London E.2.

† Pneumoconiosis Medical Panel, London N.W.1.
}

Panel in London. These subjects were referred for a number of different reasons. Most commonly an abnormal chest radiograph was noted by the referring centre, either as a result of routine examination or because of respiratory symptoms. Less often patients were referred because abnormal signs suggestive of asbestosis-namely, finger-clubbing and persistent basal crepitations-had been observed. The patients studied therefore showed a range of clinical and radiographic features, and after assessment not all of them were accepted by the Panel as suffering from asbestosis.

Terminology.-Asbestosis is defined as widespread fibrosis of the lungs, particularly but not exclusively of the alveolar walls, attributed to inhaled asbestos dust. Lung tissue was of course not available to us, and for the purposes of this study the diagnostic criteria used to designate "asbestosis" were a history of exposure to asbestos dust and a radiograph showing bilateral irregular or small round shadows with or without honeycombing, and not obviously accounted for by other recognizable disease-for example, tuberculosis, sarcoidosis, heart disease. Additional supporting features included basal crepitations, clubbing of the fingers, and a restrictive ventilatory defect without airway obstruction, but these were not used as obligatory diagnostic criteria. At the present time there is no certain way of distinguishing the clinical syndrome of cryptogenic fibrosing alveolitis occurring by chance in an asbestos worker from asbestosis, and even lung biopsy may fail to resolve the problem in some cases.

Immunological Studies.-All the laboratory studies were completed without previous knowledge of the clinical and radiographic details of the subjects. Antinuclear factors (A.N.F.) were measured by a standard double-layer immunofluorescent technique with rat liver as substrate using antisera to human $\gamma$-globulin conjugated with fluorescein isothiocyanate (Coons and Kaplan, 1950) and test serum diluted $1: 10$. Antisera were conjugated with fluorescein isothiocyanate used $1: 50$ by weight to antisera of standard protein content $(10 \mathrm{mg} . / \mathrm{ml}$. giving a final $\mathrm{F} / \mathrm{P}$ ratio of $2: 1)$. Before use the conjugates were diluted 8 or 16 times to give maximum contrast between nuclear and background fluorescence without reducing the titre of known positive control sera. Test sera found to be positive at $1: 10$ were titrated by use of increasing dilutions in the immunofluorescent test. Titres of $1: 10$ and over were accepted as positive. The immunoglobulin class of A.N.F. was identified by the same 